U.S. Department

of Transportation

National Highway

Traffic Safety

Administration

\title{
Research Agenda For An Improved Novice Driver Education Program
}

\section{Report to the Congress}

May 31, 1994

Prepared in Response to House Report 2750 Accompanying the House Committee Appropriations Bill for 1994 
This Report Was Prepared by the

Office of Program Development \& Evaluation

Traffic Safety Programs 
Technical Report Documentation Page

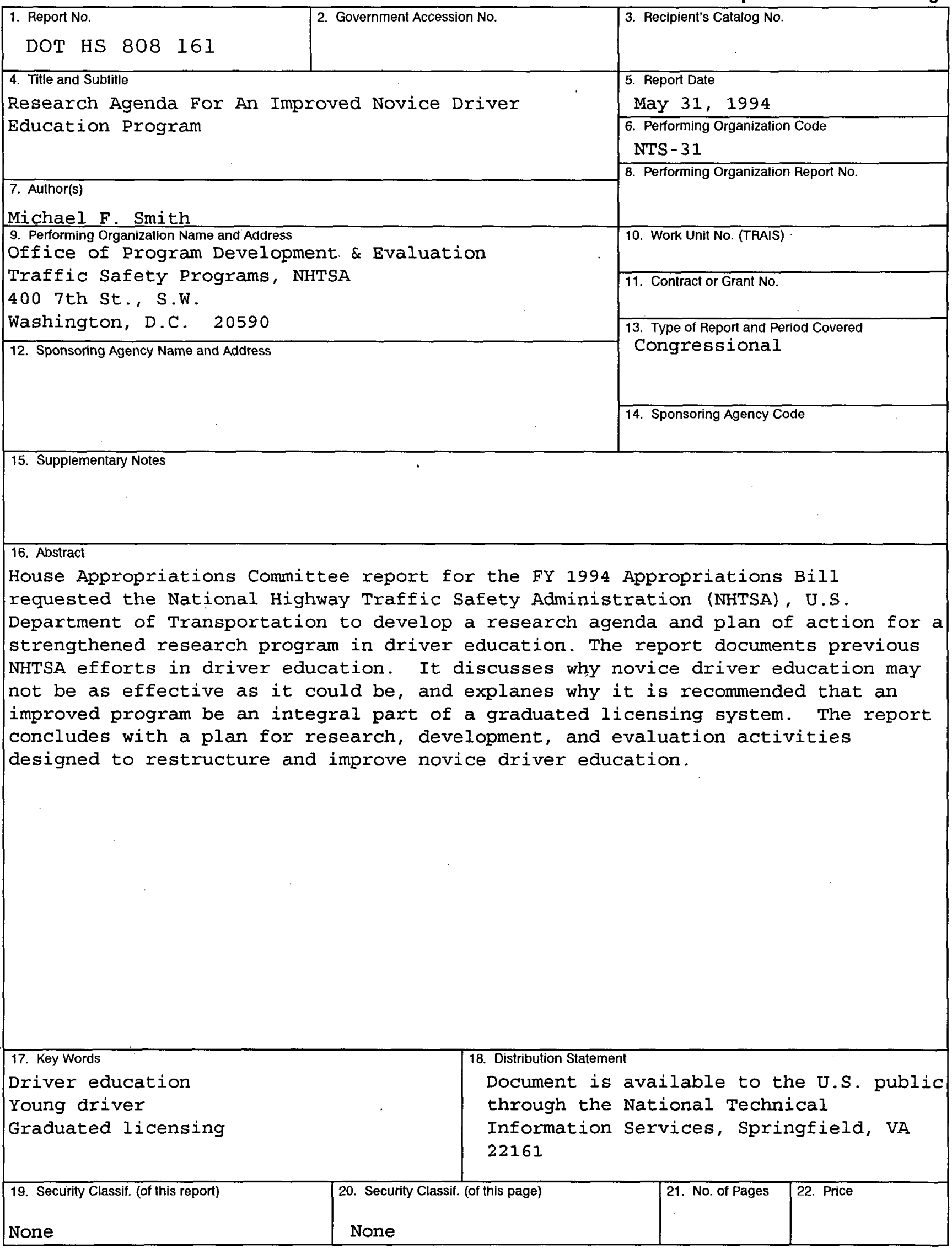

Form DOT F 1700.7 (8-72) Reproduction of completed page authorized 


\section{TABLE OF CONTENTS}

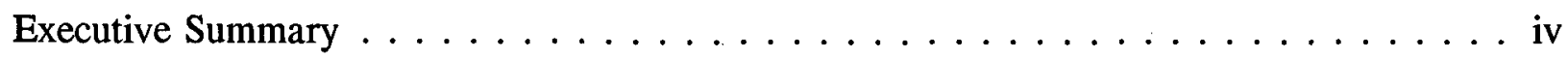

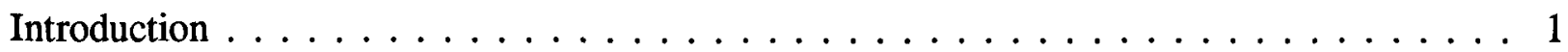

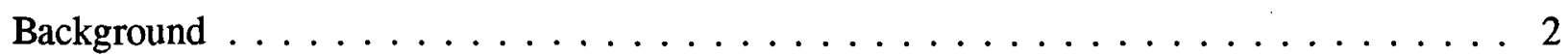

Traffic Safety Problems of Youth $\ldots \ldots \ldots \ldots \ldots \ldots$

Novice Driver Education $\ldots \ldots \ldots \ldots \ldots \ldots \ldots \ldots$

Driver Education and NHTSA . . . . . . . . . . . . 4

Driver Licensing and NHTSA $\ldots \ldots \ldots \ldots \ldots \ldots$

Results of Driver Education Risk Reduction Workshop . . . . . . . . . . . 12

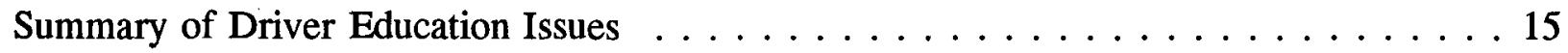

Results of SPC Demonstration . . . . . . . . . . . . . 15

Driver Education and Crash Reduction $\ldots \ldots \ldots \ldots \ldots \ldots$

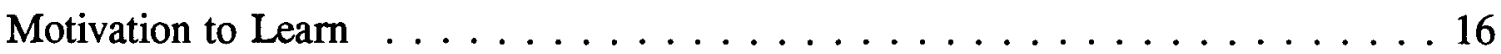

Graduated Licensing System $\ldots \ldots \ldots \ldots \ldots$

Innovative Driver Education $\ldots \ldots \ldots \ldots \ldots \ldots$

Research, Development And Evaluation Agenda $\ldots \ldots \ldots \ldots \ldots$

Graduated Licensing Demonstrations and Evaluations . . . . . . . . . . 19

Risk Taking Research $\ldots \ldots \ldots \ldots \ldots \ldots$

Two-Stage Novice Driver Education Development \& Evaluation $\ldots \ldots \ldots . . .20$

Parental Involvement In Driver Education $\ldots \ldots \ldots \ldots \ldots \ldots \ldots$

Innovative Simulation Technology $\ldots \ldots \ldots \ldots \ldots \ldots \ldots \ldots \ldots \ldots$

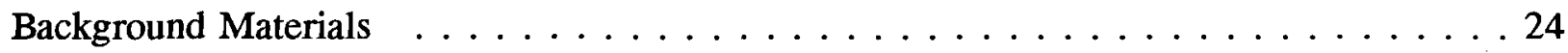




\section{EXECUTIVE SUMMARY}

The House Appropriations Committee report accompanying the FY 1994 Appropriations Bill requested that the National Highway Traffic Safety Administration (NHTSA), in consultation with the Federal Highway Administration, develop a research agenda and plan of action for a strengthened research program in driver education for youth. It requests that the report be provided by March 1994 to the House and Senate Appropriations Committees.

Traffic crashes are the number one cause of death for youth. As long as accident statistics have been kept, teenagers have been overrepresented in traffic crashes. The crash rate per mile for teenagers is four times higher than for adults.

The Agency is interested in countermeasures that will reduce the crashes, injuries, and fatalities of young drivers. Currently, effective methods include laws that require the use of occupant protection devices, nonuse of alcohol until age 21, and the loss of the driver license for major traffic convictions. Programs such as a graduated licensing system (learner permit, intermediate/provisional license, regular license) and the active enforcement of traffic laws have also been effective. For these laws and programs to be most useful, they must be backed by public education and information.

This report documents previous NHTSA efforts in driver education. These include the results of a major demonstration evaluation that was conducted in DeKalb County Georgia and a summary of a workshop held last year that resulted in numerous recommendations on how to reduce driver risk taking and improve driver education. It provides a discussion of why driver education may not be as effective as it could be, and explains why it is recommended that an improved novice driver education program be an integral part of a graduated licensing system. The report describes the range of NHTSA's educational programs throughout the school years designed to reduce the crash involvement of children and young people. It concludes with a comprehensive plan for research, development, and evaluation activities designed to restructure and improve novice driver education.

The proposed Research Agenda is based on 25 years of driver education and graduated licensing research, development, and evaluation, primarily sponsored by NHTSA, and incorporates results of research performed by States, non-government organizations and associations, and other countries. The plan is centered on developing a cost-effective twostage driver education program that is an integral part of a graduated licensing system. The first driver education stage would provide basic vehicle handling skills, and the second stage would provide for other safe driving skills, including enhanced decision making to reduce the risk taking of young drivers. The effort also includes developing procedures that would extend the role of parents, and other adults in the process of educating and training novice drivers. An assessment of current simulation technology to provide a cost-effective learning environment for new drivers will also be performed. 


\section{RESEARCH AGENDA \\ FOR AN \\ IMPROVED NOVICE DRIVER EDUCATION PROGRAM}

\section{INTRODUCTION}

The House Appropriations Committee report accompanying the FY 1994 Appropriations Bill requested that the National Highway Traffic Safety Administration (NHTSA), in consultation with the Federal Highway Administration (FHWA), develop a research agenda and plan of action for a strengthened research program in driver education. This agenda and plan was requested to be submitted to the House and Senate Appropriations Committees.

Driving is a complex and often demanding task, even for the best of drivers. Driving primarily involves controlling a motor vehicle from one point to another while complying with traffic laws and regulations. During the trip, there is constant interaction between those factors that make up the highway traffic system: the driver, vehicle, roadway, other roadway users, and the environment. The driver must obtain information from each of these constantly changing factors, decide what action to take, initiate that action, assess the consequences, take remedial action if necessary, and then repeat the process. A good driver performs these steps in a timely manner. A safe driver also performs these steps in a manner which minimizes the need to take corrective action. Luckily, most driving is done under conditions that do not require a constant, high level of attention, nor the need for advanced driving skills. However, with increased speed, changing roadway, traffic or environmental conditions, or the condition of the driver, a situation can arise for which the driver is not prepared, or is incapable of handling, and a crash occurs.

Driver education is a training program of organized learning and practice designed to provide the basic knowledge, attitudes, and skills needed to drive safely, and to provide the advanced knowledge and skills needed for safe driving performance under special circumstances. A good program should provide additional and/or more consistent information to the student than would otherwise be available. Training can enhance the level of skill, and it can provide a short-cut to the learning process. A good training program is invaluable in teaching complex skills. Driver education has the potential to be an effective tool in the preparation of new, safe drivers.

The NHTSA agrees with the House Report that improved and continuing driver education, coupled with a graduated licensing system, holds promise in reducing young driver crashes. The Agency will research, develop and evaluate an improved novice driver education program. Results from these activities will be used to develop program materials for the states, communities, and interested safety organizations and associations. 


\section{BACKGROUND}

\section{$\underline{\text { Traffic Safety Problems of Youth }}$}

Traffic crashes are the number one cause of death for youth and represent approximately 40 percent of all deaths of young people between 15-20 years of age. Over 5,900 teenagers die as a result of traffic crashes each year. While these drivers make up about 8 percent of the population, they account for about 15 percent of motor vehicle deaths. The crash rate per mile for drivers 15-20 years of age is about 4 times as high as for adults. About 40 percent of teenage motor vehicle deaths in 1993 occurred in alcohol-related crashes, and about 24 percent of teenage drivers involved in fatal crashes had alcohol involvement (i.e., the highest blood alcohol concentration (BAC) in the crash was 0.01 percent or greater). Even though these rates have decreased 18 and 22 percent, respectively, since 1982, the involvement rate is too high. Many of the crashes of novices involve outright speeding or traveling too fast for conditions. While not all young drivers are unsafe, about 15 percent of them have a crash in their first year of driving.
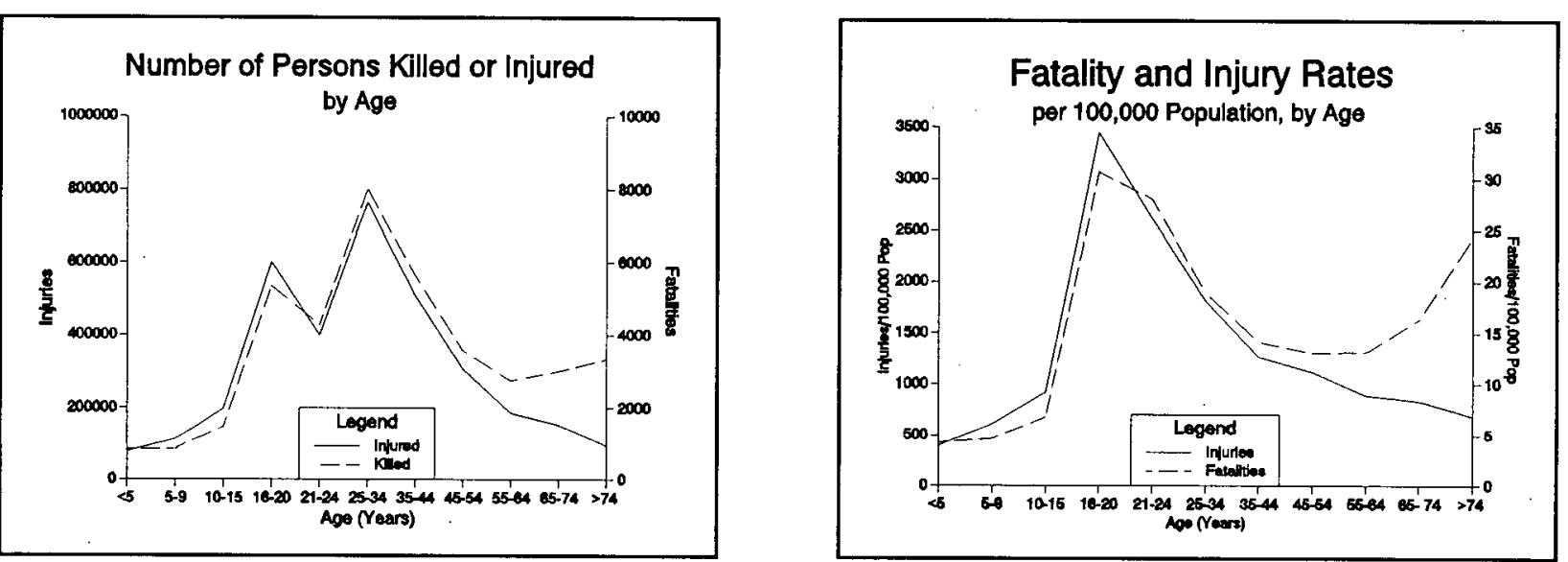

(Source: Traffic Safety Facts 1992, DOT HS 808 022, September 1993)

The extremely high injury and fatality rates seen in the first years of driving serve as a grim reminder of the need to focus on this age group. There is no simple solution to reducing the crash involvement of young people. In many cases, these crashes are not caused by a lack of knowledge of basic traffic laws or lack of basic vehicle handling skills. The issue is more complex. The problem appears to be more a function of the developmental characteristics of youth and their propensity to take risks, their belief that they are invincible, and their susceptibility to peer pressure. Part of the problem is caused by the various mores and habits of our culture, including the accepted use of alcohol for a variety of situations and celebrations. Add to this problem the limited driving experience, sometimes poor attitudes, and differing perceptions of the risk of various traffic situations, such as high speed driving, and a significant lack of good judgment in critical driving situations, and you have an increased probability of unsafe traffic behaviors that frequently result in a crash with injuries or death for young drivers. 


\section{Novice Driver Education}

Education clearly plays an important role in addressing the traffic safety problems of youth. NHTSA directs considerable effort to young people throughout their school years regarding pedestrian, bicyclist, and motorcyclist safety; alcohol and driving; and safety-belt use. The early involvement of young people in motor-vehicle crashes underscores the need for safety education prior to their driving years.

Providing instruction to individuals on how to drive is not a new concept. The first known novice driver education program was developed in 1916. The first textbook for safety education was published in 1919. In the early 1930s, the first recorded in-school driver education class was taught, and by the late 1930s, a small number of colleges were offering courses designed to prepare driver education teachers.

The first National Conference on High School Driver Education was held in 1949. One of the recommendations was that a minimum novice driver education course should be "30 \& 6." That is, 30 hours of classroom instruction and 6 hours of behind-the-wheel instruction. This formula is still followed today in many driver education programs.

In 1952, Allstate Insurance Company started offering discounts to students who completed a high school driver education program. Other insurance companies followed. Also during the 1950 s and 1960s, several evaluations were conducted which proclaimed the effectiveness of high school driver education. What followed was the promotion of high school driver education and the almost complete acceptance by the general public that novice high school driver education was an effective approach for reducing the crashes of new drivers. This resulted in an explosion of high school driver education programs across the Nation when, in fact, the crash reduction potential of these programs was unknown.

In the early 1970s, as the knowledge of evaluation design grew, closer examination of the earlier driver education evaluations showed that they were seriously flawed and the crash reductions touted for driver education could have easily been caused by other factors (e.g., student volunteer bias) or poor evaluation design (e.g., lack of adequate control groups, random assignment of students to training). The actuarial data of insurance companies that offered discounts for driver education did show that students who took driver education had fewer crashes than did those who did not take it; however, such actuarial data does not show "cause and effect." It only indicates these individuals have better driving records, not why.

Other issues evolved concerning the driver education instructor. As driver education became popular, there were not enough trained driver education teachers to meet the demand. Teachers were borrowed from other subject areas to teach driver education part time. Many teachers taught for the extra money. Many received little, if any, training in teaching driver education. Besides affecting the potential quality of instruction, it also caused driver education in many states to be viewed as less important than more traditional high school courses. This perception by both teachers and administrators meant that little effort was expended for improving driver education. 
The popularity of high school driver education peaked in the late 1960s and early 1970s when up to 14,000 high schools provided some type of training program to over 2 million teenagers per year, or around 70 percent of those students who were eligible. Also at this time, about 30 states provided at least partial reimbursement to high schools to off-set local expenses to train driver education students.

There are no data on the number of students who currently take high school driver education. It appears that fewer than half of all high schools offer any type of driver education. However, about 25 States require some form of driver education if a young person wants to be licensed before age 18 .

The majority of teenagers currently do not receive any type of formal high school driver education training. They learn from their parents, friends, or by other means. Some do learn through commercial companies. Where programs are offered in the high schools, some have the in-vehicle training provided under contract by commercial companies. Many of the high schools that provide driver education require the parents or students to pay for all or some part of the training.

There are no Federal requirements for driver education programs. Training programs are regulated by the States, but the requirements can be minimal. For example, most States do not have a program requiring achievement of specific safe driving objectives. Where high school driver education is given, it often is no more than two dozen hours of classroom instruction and a couple of hours of behind the wheel training. Such a program is by design very basic and often results in nothing more than the student getting licensed. This was not the intent of those safety educators who developed driver education.

\section{Driver Education And The National Highway Traffic Safety Administration}

The National Highway Safety Bureau (NHSB), the forerunner of the NHTSA, was created by Congress under the Highway Safety Act of 1966 . Originally, the Bureau was part of the Federal Highway Administration (FHWA) within the new United States Department of Transportation. In 1970, the Bureau was elevated to the status of an Administration and charged with the responsibility to reduce crashes and resultant injuries and deaths of roadway users. The Highway Safety Act of 1966 also required the establishment of Uniform Standards for State Highway Safety Programs to assist the States and local communities in organizing their highway safety programs.

Eighteen (18) State Highway Program Standards accompanied by Program Manuals were developed by the NHSB in the late 1960s. The Standards were:

1. Periodic Motor Vehicle Inspection

2. Motor Vehicle Registration

3. Motorcycle Safety

4. Driver Education

5. Driver Licensing

6. Codes and Laws 
7. Traffic Courts

8. Alcohol in Relation to Highway Safety

9. Identification and Surveillance of Accident Locations

10. Traffic Records

11. Emergency Medical Services

12. Highway Design, Construction, and Maintenance (now handled by FHWA)

13. Traffic Engineering Services (now handled by FHWA)

14. Pedestrian Safety (now jointly administered by NHTSA \& FHWA)

15. Police Traffic Services

16. Debris Hazard Control and Cleanup (now handled by FHWA)

17. Pupil Transportation Safety

18. Accident Investigation and Reporting

At the time (1967), Highway Safety Program Standard \#4, Driver Education, appeared to have the potential to be an excellent tool for reducing the crashes of novice drivers. Driver education was very popular at the time, earlier evaluations had found the training to reduce crashes, it had strong face validity, and it had been around for many years.

In the late 1960s and early 1970s, the Agency supported the Driver Education Standard by providing state and community Highway Safety Grant Program funds (Section 402) to the states to improve and evaluate their driver education programs. The states used these funds primarily to expand their programs and spent very few dollars to improve the quality of the programs or to evaluate them.

Because of the potential of high school driver education to reduce crashes, the Agency used Highway Safety Research and Development funds (Section 403) to initiate a major program of research, development and evaluation. The primary intent of this program was to determine the effectiveness of high school driver education to reduce the crashes of novice drivers.

Four contracts were awarded to review the state-of-the-art of driver education and to determine the best approach for establishing the effectiveness of this type of training. Two National Symposiums were held in 1968 and 1969 to review existing information and gather additional information. In 1969, the National Research Council of the National Academy of Sciences was asked to consolidate the results from the Symposiums and the four initial contracts and recommend a program of research, development and evaluation. The Agency used these recommendations to guide its driver education research.

The first research effort was to examine the behaviors needed for successful driving, a driver task analysis (1970). Over 1700 driving behaviors were identified and rated for their criticality. Criticality was based on the frequency of the behavior, likelihood that the behavior would be performed incorrectly, likelihood the incorrect performance would be related to crash involvement, and the potential severity of the crash. Instructional objectives (1971) were then developed based on these identified critical driver behaviors. This was followed by the development of specifications for a novice driver education curriculum (1973). Two research curricula were developed: the Safe Performance Curriculum (SPC), a model research curriculum, and the Pre-driver Licensing Curriculum (PDL), a condensed 
version of the SPC. (More information on these courses will be provided later in this report.) In addition, a variety of driver knowledge and performance tests were developed (1974).

These curricula (SPC \& PDL) were pilot tested in Kansas City, MO. The pilot test provided invaluable information relative to conducting the program and identifying problems associated with attempting a large scale evaluation of driver education. Preliminary data did show that the curricula could significantly improve the knowledge of students. The crash reduction impact of the program was not tested at this time.

The operational demonstration and evaluation of the two curricula was initiated in 1976 with the Dekalb County School District (a suburb of Atlanta, GA). The Safe Performance Curriculum Driver Education Demonstration Project had the primary objective of determining the crash reduction potential of competency-based driver education as compared to no formal training.

The following provides a summary of procedures needed to prepare for the demonstration and evaluation.

o Based on the results of the pilot testing, almost every aspect of the program was revised. This included the performance tests (both knowledge and skill), and many of the administrative procedures for conducting the demonstration and evaluation. The SPC and PDL were updated, modified and then reviewed by national experts. Computer programs were written to handle the assignment of students, storage of data, and to assist in the analyses of results.

o $\quad 18,000$ students from 24 high schools had to be randomly assigned to one of the two curricula or a control group (no formal driver education provided by the schools). The random assignment took school, sex, grade point average (GPA), and social economic status (based on several economic-related variables) into account. This procedure was designed to ensure that the three groups were essentially the same and did not differ with respect to characteristics that might be related to crash involvement risk.

o Four (4) driver education sites were developed in different geographic regions of the county that together could handle over 5,000 students a year. Students were to be bused to the driver education sites and then returned to their schools during the operational phase of the evaluation. Each of these driver education sites included an off-street practice driving range, classroom simulators (car seat with driver controls, where students drove along with a film), classroom, offices for the instructors, and other support equipment and facilities (e.g., rest rooms).

o Staff was hired, including 25 instructors and 8 aides. Instructors received 10 weeks of training before the evaluation was started and periodic in-service training during the project. Instruction was monitored throughout the project. 
The two driver education courses, the SPC and PDL, including instructional procedures and materials, were developed specifically for the evaluation. The SPC included almost 80 hours of instruction using classroom, simulation, range and on-street practice, and allowed for independent study and parent participation. The SPC covered all aspects of what was considered to be important for a new driver to know (vehicle control skills, environmental factors, complex perceptual skills, driver impairments, emergency situations, and personal readiness).

The PDL included almost 30 hours of formal instruction also using classroom, simulation, range and on-street procedures. The PDL course was, to the extent possible, a condensed version of the longer SPC. Instruction in the PDL course concentrated on information and training for basic vehicle control skills, while the major aspects of safe driving skills were covered by reading assignments.

The project instructors were highly trained, motivated, closely supervised, and taught both courses to minimize instructor influence on the evaluation outcome. The instructors closely followed curriculum guides that detailed the educational objectives and procedures for each course. Students in both courses were tested on a regular basis and given remedial assignments if they failed any of these tests. Everything possible was done in the project to provide quality driver education.

The SPC and PDL were taught for three consecutive years starting with the 1978 school year. A number of interim reports were done throughout the project. A final project report was printed in 1983, and a follow-up evaluation summary was presented in 1987.

At the project's inception, it was anticipated that a well designed, more extensive driver education course would be moderately effective (10-15 percent) in reducing the crashes of young drivers. It also was assumed that a longer course (SPC) would be significantly more effective than a shorter course (PDL).

A summary of results from the 1983 project final report follows:

o A total of 16,338 students were assigned to one of the three groups. Of these, 14,743 (90 percent) obtained a driver license. Out of the 10,894 students assigned to the two training courses, only 7,512 (69 percent) completed the course to which they were assigned and obtained a license.

o Analysis at the random assignment level (includes all students, licensed or not) showed no significant differences between the mean number of crashes or convictions for students who received training (both SPC and PDL combined, see below) compared to students who did not receive training during their first two years of driving.

o Compared to control students, those students who were assigned to training and were licensed had significantly fewer crashes during the first six months of driving, but the effect was gone by the end of the first year of driving. 
o Compared to the controls, those students assigned to training and licensed had significantly fewer convictions during the first 12 months of driving, but the effect was gone by the end of 18 months of driving.

o In summary, for all practical purposes, there was no significant reduction in crashes or traffic violations for those students who received training compared to students who received no formal training.

A major difficulty with this evaluation was the small number of students who had acquired any significant amount of driving experience. For example, only half of the trained students had at least two years of driving experience. Because of the small number of students who had any extended driving experience, the two training groups had to be evaluated together. For these and other reasons, it was felt that this analysis was not a fair evaluation of the program. Thus, the NHTSA decided to continue to track the driving records of the project students until the majority would have at least four years of experience and then reanalyze the data. The State of Georgia agreed to maintain the driving records of the project students.

In 1986, the driving records of the students were reevaluated. The following is a summary of the follow-up evaluation.

o The vast majority (93 percent) of students had accumulated some driving experience. About 7 percent of the students never obtained a driver license, at least not in Georgia. It was found that 87 percent of the students now had at least four years of driving experience.

o There were NO significant reductions for SPC (long course) students in the number of crashes as compared to control students.

o There was a small (around 6 percent) but significant reduction in the number of crashes for PDL (short course) students as compared to controls with no formal driver education.

o Both PDL and SPC male students had significantly fewer total convictions during their first six years of driving than did controls (average of 10 percent fewer for PDL and 9 percent for SPC). No differences were found for females.

o For all students combined, the largest percent who had a crash had it in the first year of driving (about 20 percent). By the end of six years, 60 percent of the male and 46 percent of the female students had a reported crash.

- For all students combined, about 27 percent of them had at least one conviction in their first year of driving. After six years of driving, 81 percent of the male and 56 percent of the female students had at least one conviction. 
It also was found that a large number of project students were no longer licensed in Georgia. In fact, the number of missing students was large enough that it made no sense to continue to track the driving records of those students who were left. Georgia thus removed the project from their files.

In summary, only one of the training courses (the short one) resulted in any significant reduction of crashes, and not nearly at the level expected of the training. Even with training, large numbers of students were having traffic convictions and crashes during the first few years of their driving. These and other driver education issues will be discussed in more detail later in the report.

Although NHTSA's driver education initiatives in the 1970s and early 1980s concentrated on evaluating the crash impact of the SPC and PDL curricula, other related efforts also were conducted. These included research to improve instructor qualifications and instructional procedures; determine the causes of young driver risk taking; make the use of off-road training more efficient; investigate the potential of using in-depth crash data as a basis for training crash-avoidance; and improve driver performance skill testing. Other studies investigated parental involvement in novice training, use of innovative teaching procedures (e.g., holographic projection of simulated hazards through a vehicle windshield), and identified the requirements for a $\mathrm{K}-12$ safety education program.

Other Agency driver training activities included the development of a driver improvement program for use by state driver licensing authorities for problem drivers, and providing technical assistance to the American Association of Retired Persons (AARP) in the development and evaluation of their driver training program "55 Alive, Mature Driving."

Several driver education component programs were developed and tested including alcohol safety, use of child safety seats and safety belts, speed management, and energy efficient driving techniques. These educational modules were designed to be easily integrated into existing driver education programs or as stand-alone activities.

As previously noted, the Agency's first national driver education planning effort was conducted in the late 1960s. The second national effort for driver education research, development, and operations was initiated in the late 1970s (as a part of a review of all Section 403 activities). This effort reviewed driver education activities of the past 10 years and provided recommendations for future Agency activities.

In 1981, Congress required the NHTSA, in conjunction with the FHWA, to determine those highway safety programs most effective in reducing crashes, injuries and fatalities. These programs would be the emphasis areas for Section 402 funding. The areas administered by NHTSA determined to be national priority program areas were: Occupant Protection, Alcohol Countermeasures, Police Traffic Services, Emergency Medical Services, and Traffic Records. Roadway Safety, an area administered by FHWA, also was determined to be a national priority area. 
Based primarily on the SPC demonstration evaluation results, high school driver education was determined not to be a priority program area under the Section 402 program. Section 403 funding for driver education programs also was reduced.

In 1987 and in 1991, the NHTSA and FHWA reconsidered whether changes should be made to the list of national priority program areas. In a 1988 final rule, motorcycle safety was added to the list of priority programs, and in a 1991 final rule, pedestrian and bicycle safety was added. Driver education was not included on the list.

\section{Driver Licensing and The National Highway Traffic Safety Administration}

Driver licensing and driver education have always had a common interest, ensuring safe driver performance. In a number of states, completing high school driver education would exempt the applicant from taking the driver licensing road test. A major criticism of many current driver education programs is that they only prepare the student to get a license. As the proposed driver education program will involve the driver licensing system, it is appropriate to briefly review the Agency's involvement with driver licensing.

State driver licensing activities have the primary function of ensuring that applicants meet minimum knowledge and skill proficiency levels necessary for safe driving, and that drivers falling below acceptable levels of performance are promptly identified through examinations and review of individual driving records. Driver license testing is offered so that individuals may improve their performance, and States may deny licensure to those who are unable to meet minimum performance standards.

The Agency's early driver licensing research (1969-1984) concentrated on the development of improved and standardized driver screening techniques and procedures, knowledge and skill tests and testing procedures, and driver improvement activities. Driver manuals, knowledge tests, off-street skill tests, and on-street tests for applicants of motorcycles, passenger vehicles, and heavy trucks, tractor-trailer combinations, and large buses were developed based on the agency's recommended classified license system. Examiner and administrator manuals and a variety of other supporting materials also were developed.

In the late 1980s, the NHTSA provided staff and technical support to FHWA in their development of the Commercial Drivers License (CDL). This technical support continues to be provided to the American Association of Motor Vehicle Administrators (includes state driver licensing officials) and to FHWA when requested.

Driver screening research (1971-1979) concentrated on improving vision testing techniques and procedures. Experimental automated vision testers were developed and field tested. Because of major equipment reliability and maintenance problems, the effort was not found to be useful to licensing agencies.

Driver improvement research activities (1972-1982) resulted in a recommended system of dealing with problem drivers. The system provides for early intervention, scaling the severity of action to the seriousness of the traffic offense, and providing for gradual exit 
from the driver licensing system. It incorporates three levels of action (warning, instruction, and sanction), uses a simple point system to identify drivers for action, and provides for modified treatment of youthful and alcohol offenders.

During this time period, it became clear through the work of NHTSA and others around the world, most noticeably in Canada, Australia and New Zealand, that graduated driver licensing could reduce the crashes of new drivers. The NHTSA efforts to develop and evaluate graduated licensing (1977-1983) resulted in a model entry system for novice drivers. This licensing system has been adopted by the American Association of Motor Vehicle Administrators (1989) and recommended to their member States.

Evaluations of these licensing systems have found crash reduction impacts of up to 16 percent (Oregon, for males), with most falling between 5 and 10 percent (e.g., Maryland (5 percent), California ( 5 percent), Ontario, Canada ( 9 percent), New Zealand ( 8 percent)). The New Zealand system is unique in several ways. It is the first to include driver education as an integral part of gaining a full driver license, to include new drivers up to 24 years of age, and to include motorcycle licensing as a part of the graduated system.

Graduated licensing is a three tier system that gradually introduces new drivers to the complex system of driving in a controlled manner. The three tiers are a learner permit, intermediate or provisional license, and a regular license. Example components and restrictions of each tier are:

o Learner's Permit

o Licensed adult (at least 21 years of age) required in vehicle at all times.

o All occupants must use safety belts.

o Learner must remain conviction- and crash-free for six months to move to next stage.

o Permit cancelled with any alcohol-related offense and the learner must wait at least six months prior to reapplying.

o The license looks different than other driver licenses.

o Intermediate/Provisional License

o Zero alcohol while driving (usually $0.02 \mathrm{BAC}$ ).

o $\quad$ All occupants must use seat belts.

o No late night driving except with an adult.

o Applicant must demonstrate safe driving performance (no traffic convictions or crashes) for one year. 
Driver improvement programs are designed especially for youth such that:

- Improvement activities (warning letter, education/information, suspension) are initiated sooner (e.g., at a lower point level) than for regular license holder.

- $\quad$ Any major traffic conviction or crash result in license suspension or an extended provisional period.

o The license looks different than other driver licenses.

While 11 states have some form of a three-tier licensing system, none of these states use all components of the three-tier program outlined above. A number of additional states have one or more components of the recommended system, but these components are not part of the State's licensing program. For example, eight (8) states have 0.02 percent or less BAC for drivers under age 21, but only two (2) have this restriction as part of their licensing system.

\section{Results of Driver Education Risk Reduction Workshop}

The NHTSA convened a panel of national and international experts in traffic safety in April 1993. There were representatives from Federal and State government, private sector, academia, and traffic safety associations. The group's assignment was to identify research and development needs for training designed to reduce young driver risk taking and improve their decision making skills.

A background issue paper that provided an overview of young driver risk taking literature was used as a starting point for the discussions. Deliberations of the group covered several areas including: issues and definitions involved in analyzing young driver risk taking, training as a means of reducing risk taking, ways to restructure current driver training efforts, and the requirements needed to improve novice driver education.

The Workshop resulted in a number of general findings and recommendations. The following summarizes the general findings followed by highlights of the specific recommendations:

o No one traffic safety countermeasure will drastically reduce the crashes of young drivers. A "systems" approach is needed that includes driver licensing, driver education, traffic law enforcement, and public information and education.

o Novice driver education as often presented (e.g., 30 classroom hours \& 6 behind-thewheel) does result in most students getting a driver license; however, it does not appear to develop safe driving behaviors that reduce the crashes of young drivers.

o Driver education should be an integrated part of a graduated driver licensing system. Keeping a driver license will provide the student with the motivation to learn safe 
driving behaviors. Being part of a graduated license system will require the student to practice safe driving.

o Teaching a new driver to be a safe driver needs to be done over an extended period. Instruction should be self-paced, where possible, with appropriate feedback, and with progress being determined by skill and knowledge testing.

o Training that emphasizes safe driving skills should only be given after the student has some amount of basic behind-the-wheel experience.

- Novice driver training must include all types of driving situations that will be encountered by the new driver.

o There is both "positive" and "negative" risk, and that risk taking is probably an unavoidable component of youthful behavior. The challenge is how to best manage and reduce youthful risk taking that results in negative consequences (e.g., traffic violations).

The workshop also identified over 30 specific research recommendations, some of which are highlighted below:

o Determine when attitudes and decision making patterns are formed in young people and how and when those patterns best can be influenced by education.

o Determine why driving experience (e.g., improved visual information processing such as more efficient searching, and hazard recognition) and maturation (e.g., older novices have fewer crashes than younger novices) reduce crashes. Determine if either process could be simulated or expedited in some form of training or other means.

o Adapt divided-attention procedures to train young drivers to attend to multiple tasks. Investigate video and other electronic games as method of multi-task training.

o Investigate the successes of mental rehearsal for certain types of skills and determine if such activity is appropriate or possible as a part of novice driver training.

o Review state-of-art simulation technology and determine usefulness for training and educating new drivers. Determine which aspects of driver education are best suited to simulation.

o If a new driver education program is developed, determine changes needed for the preparation of teachers and instructors. Establish an administrative and development process that will upgrade the new driver education program as necessary.

o Develop a standardized road test that will adequately test the qualifications of a novice driver to pass driver education. 
o The NHTSA should be more active in investigating how to deal with the youth risk problem, and that research is needed.

In summary, it was felt that current novice driver education is not doing a very good job in motivating youngsters to drive safely. The group did feel that driver education is a very important part of the systems approach to reduce crashes, but it should be redefined and redeveloped to better address the needs of youthful novice drivers. For driver education to be most effective, it should be an integral part of a graduated licensing system and the training should be distributed over time. 


\section{SUMMARY OF DRIVER EDUCATION ISSUES}

Current novice driver education does not seem to reduce unsafe driving behaviors by young drivers substantially. Thus, existing methods and systems of delivery for driver education should be reviewed and updated. New methods and approaches to driver education must be developed. These procedures must place greater emphasis on experience-related factors that decrease crash risk.

\section{Results of SPC Demonstration}

One of the first issues to be resolved involves the results of the Dekalb County Georgia driver education demonstration and evaluation project. The evaluation analysis found a statistically significant crash reduction ( 6 percent), but only for the short course. Given the positive results of other complex skill training programs, it would appear that driver education has the potential to have more of an impact than results to date have indicated. So, assuming that driver education has the potential for at least a 10 percent reduction in crashes, was there a problem with the evaluation of the program?

A reanalysis of the project as it was developed, conducted, managed, and evaluated, indicates that nothing was wrong. The project was conducted as well as it could be in an operational evaluation. Thus, the issue of not getting any major reduction in crashes does not stem from the project per se, but must be the result of something else. It stems from the manner in which novice driver education is provided in the United States, that is, "when" and "how."

\section{Driver Education and Crash Reduction}

Crash reduction from driver education probably comes from the application of safe driving strategies, not from an application of basic vehicle control skills. For example, there is some evidence that young males can have superior vehicle handling skills and still have crashes (probably because of poor attitudes, poor decisions, risk taking, alcohol impairment, etc.). We know that older and more experienced drivers have fewer crashes, and there is evidence that older novice drivers have fewer crashes than younger novice drivers. All in all, this suggests that the major impact from driver education will come from teaching safe driving strategies (good decision making resulting in risk reduction), not in the teaching of basic vehicle handling skills. However, as is true for all complex tasks, individuals must have a foundation in the basics before more complex tasks can be mastered. In the case of traffic safety, a foundation of basic vehicle handling skills must be learned before the novice can consistently learn and practice safe driving strategies.

Trying to teach a new driver both basic vehicle control skills and safe driving skills at the same time is probably inappropriate or, at best, inefficient. The new driver may be so preoccupied with learning basic vehicle control skills, that he/she does not have the capacity (or motivation) to learn safe driving strategies. If this is true, then "when" we teach safe driving must be changed. Currently, for all practical purposes, most driver education 
programs are trying to teach both basic vehicle handling and safe driving strategies at the same time.

\section{Motivation to Learn}

What motivates a new driver to learn to be a safe driver also must be considered, and probably also requires that "when" we are trying to teach driver education be changed. We cannot teach anything to individuals (young or old) who are not motivated to learn or who are not ready to learn. All the safe driving knowledge and skill that could be taught is of no value if drivers are not motivated to apply it while driving. The driver license can provide substantial, and consistent motivation to most teenagers. The majority of youngsters (as well as most people) want a driver license, and once they have it, they want to keep it. This is a very powerful motivator, and can be used to assure that a minimum level of safe driving strategy be learned by novice drivers.

\section{Graduated Licensing System}

As discussed, any new approach to driver education must consider when it is taught and how individuals will be motivated to learn and be a safe driver. A graduated driver license program could provide this needed motivation to novice drivers. Such a program increases driving privileges so long as the license holder demonstrates responsible and violation free driving behavior. The program allows for progressive learning, and provides an opportunity for novices to gain behind-the-wheel experience under more controlled conditions. Driver education would provide information and procedures for being a safe driver, taught at times when the driver is more receptive to learning.

\section{Innovative Driver Education}

It is the graduated driver licensing system that would provide the foundation for a new approach to teaching driver education. This approach would spread the learning over extended periods, at a minimum over a two-staged driver education program. The first stage of driver education would occur during the first tier of the graduated license program - under a Learner Permit. This stage of the driver education would provide only initial instruction, concentrating on basic vehicle handling skills, and essential safety concepts (e.g, rules of the road). The instruction could be taken in school, be provided by parents or other adults, or by other means. The novice would be driving under a restricted Learner Permit (e.g., zero $\mathrm{BAC}$, required use of safety belts, adult in vehicle at all times) while gaining basic vehicle handling skills.

Potential topics that might be taught during this stage are: requirements of the graduated license system, basic safety concepts and traffic laws, occupant protection, initiating and ending a drive, accelerating, braking, stopping, turning, tracking (i.e., keeping it between the lines), maintaining speed, parking, basics of communication with other road users, and basic driver factors (e.g., influence of alcohol on driving). 
After a minimum period of six months the novice would receive an intermediate/provisional license. Certification would be required that the novice had received instruction in basic vehicle control skills and had six months of supervised experience. This certification and the passing of a basic road test would be required before an intermediate/provisional license would be issued.

After at least six months of additional experience under the provisional/intermediate license, the second stage of the driver education program would be given. This stage of driver education would be an accredited program provided by a certified instructor. It could be presented within secondary or trade schools or by the private sector. The program would concentrate on safe driving skills and procedures, including perceptual and decision-making skills. By teaching safe driving skills after the novice had obtained behind-the-wheel experience and a minimum level of basic vehicle control capability, the novice could better concentrate on developing safe driving procedures. Instruction in safe driving strategies would now be more effective as it would be more meaningful to the novice.

Potential topics that might be included in this stage of driver education are: decisionmaking; risk taking, including use of alcohol and speeding; perceptual skills, including visual habits; vehicle factors, including handling capabilities of the vehicle and importance of vehicle maintenance; environmental factors, especially those that relate to vision, and road surface conditions and traction; other driver factors, including attitudes, stress, anger, drugs, the dangers of mixing drugs (e.g., alcohol and allergy medicine), and the social responsibilities of driving, including interacting with other roadway users; trip planning and fuel economy; and, an extensive end-of-course knowledge, attitude, and drive test.

The actual content of both the first and second stages of the driver education program will need to be determined through a variety of development efforts. More information is provided in the next section of the report. 


\section{RESEARCH, DEVELOPMENT AND EVALUATION AGENDA}

This report addresses the issue of how to improve novice driver education programs. The Agency, states, communities and private concerns have many other activities and programs designed to improve attitudes and increase knowledge and skill to reduce the crash involvement of children and youth. The Agency recognizes that no single approach can adequately address children and youth traffic safety problems. To that end, a comprehensive, multi-disciplinary approach is used to address the issues of this population. These efforts start early and continue through the high risk years. Education, information and prevention programs play a primary role in developing knowledge, positive attitudes, and safe behaviors for younger age groups, while legislation, enforcement and sanctions are more common for encouraging safe behaviors for older youth. Starting at the youngest ages, examples include child safety seat requirements; pedestrian and bicyclist safety education and training programs; a variety of prevention and education programs including recognizing the effects of alcohol and other drugs; laws that require use of occupant protection devices (e.g., bicycle and motorcycle helmets, seat belts); and loss of driver license for any alcohol involved traffic infraction for youths under the drinking age.

The research, development and evaluation activities proposed in this report are predicated on one or more states initiating a graduated licensing system as recommended by the American Association of Motor Vehicle Administrators (AAMVA) and NHTSA. It is only within the framework of a graduated licensing system that students will be motivated to learn essential safe driving behaviors. Because the new driver education program would operate within a graduated licensing system, the proposed activities will be limited if no state has such a system in place.

Several general development areas are proposed that address the critical issues surrounding current novice driver education. First and foremost, novice driver education research and development needs to be initiated that establishes an extended driver education program as an integral part of a graduated licensing system. Within such a program, there are numerous educational procedures (use of parents), and processes (simulation) that need to be revisited and, if appropriate, development initiated.

Related research and evaluation efforts currently planned or underway are also included in this plan. This is necessary to show the relationships between the proposed driver education plan and these existing efforts. Table 1, presented at the end of the section, provides overall schedules for the proposed efforts. These schedules take into account the fact that there currently is no state that has a graduated system with all the components that the NHTSA and AAMVA recommend, and none has the innovative, two-staged proposed novice driver education program. 


\section{Graduated Licensing Demonstrations and Evaluations}

Any new approach to driver education must consider when it is taught and how individuals will be motivated to be safe drivers. A graduated driver license program could provide this needed motivation to novice drivers. Such a program increases the driving privileges so long as the license holder demonstrates responsible and violation free driving behavior. Graduated licensing allows for progressive learning, and provides the opportunity for novices to gain behind-the-wheel experience under more controlled conditions.

A Request For Proposal (RFP) is going to the states in FY 1994 for the evaluation of various components of a graduated driver licensing program. These components are those that are currently recommended by the AAMVA and NHTSA. It is the intent of these evaluations to help determine which of the various components of a graduated system are most likely to reduce the crash risk of youthful drivers.

Starting in FY 1997, the intent is to demonstrate and evaluate a complete graduated licensing system. This system would include the new integrated two-staged driver education component and those licensing components found effective in the earlier evaluations. The evaluation will determine the impact that the driver education component will have on the total graduated licensing system. Evaluation design considerations would include comparisons between a state that has the total system and a state that does not have the new innovative driver education component, and pre-post comparisons within each state as it implements the new driver education program. This multiple approach was used in the Agency's earlier evaluation of MD's provisional licensing system. The evaluations would include both administrative and impact measures. Impact measures would include knowledge, attitudes, and skills of the youngsters, and comparisons of driving records to determine the crash reduction potential of the programs.

It is hoped that states will initiate a complete graduated licensing system before FY 1997. If not, then the proposed demonstration will need to be delayed until at least one state does have such a system.

\section{Risk Taking Research}

Past research suggests that young drivers often are unaware of important aspects of driving risk. It also appears that the risk taking of young people stems from more than a lack of knowledge. That is, norms, perceptions, cognitive abilities, attitudes, culture, lifestyle, and situational pressures all may contribute to poor decisions regarding driving. These factors influence the young driver to engage in activities that may result in a crash, but the activities may have other consequences that are perceived by the teenager as positive.

In FY 1993, the Agency initiated research to better understand the risk taking of young drivers. The Agency will continue this risk taking research in parallel with the proposed driver education research. It is anticipated that enough information will be available starting in FY 1995 from the current risk taking work to initiate development of an improved decision-making component for the driver education program. For example, such an effort 
might provide more useful risk taking perceptual information to novice drivers so they can improve their decision-making. Another possibility would be to identify new training procedures that provide complex information to young drivers in a form more useful to them.

\section{Two-Stage Novice Driver Education Development \& Evaluation}

The graduated driver licensing system provides the foundation for a new approach to teaching driver education. This new approach would spread the formal learning over an extended period. The first stage of driver education would occur during the first tier of the graduated license program - under a learner permit. Driver education at this stage would provide only initial instruction, concentrating on basic vehicle handling skills, and essential safety concepts (e.g, rules of the road). Instruction could take place in school, be provided by parents or other adults, or by other means. Adequate information and procedures that could be easily used would be provided to the student, parent or adult. The novice would be driving under the restrictions of a learner permit while gaining basic vehicle handling skills.

After a minimum period of six months the novice could receive an intermediate/provisional license. It is proposed that certification be required that the novice had at least six months supervised experience in basic vehicle control skills. This certification and the passing of a basic road test would be required before an intermediate/provisional license would be issued.

The second stage of the driver education program would be given only after the novice driver had at least six months of additional experience under the provisional/intermediate license. It is proposed that this stage of driver education be an accredited program provided by a certified instructor. It could be presented within secondary or trade schools or by other means through the private sector. The program would concentrate on safe driving skills and procedures, including perceptual and decision making skills. By teaching safe driving skills after the novice had obtained behind-the-wheel experience and a minimum level of basic vehicle control capability, the novice could better concentrate on developing safe driving procedures. Instruction in safe driving practices would now be more effective as it would be more meaningful to the novice.

The curriculum content and other specific aspects of both the first and second stages of the driver education program will be determined through the development effort initiated in FY 1995. Much of the information to be taught in the two stages either is currently available or will be when the program will be developed. Thus, this effort will make use of available driver education development and evaluation results. The new driver education program will be pilot tested, demonstrated and evaluated in the graduated license system demonstration to be initiated in FY 1997. Assessment of the program's impact will include knowledge, attitudes, and a variety of skills. The assessment of skills will include, driving performance, decision making, and perceptual strategies.

It should be noted that it may be difficult to find a state willing to incorporate the requirements of the proposed two-staged program as an integral part of a graduated licensing system. However, given the potential effectiveness of such a system, it will be well worth the effort to implement and test it. The Agency hopes that states will implement such a 
system with incentive grants (e.g., for evaluation). However, many states will require new or revised legislation before such a system could be implemented. Whenever state legislation is required or needed, schedules are subject to delay.

\section{Parental Involvement In Driver Education}

Parents, guardians, or other adults must play a greater role in the education and licensing of novice drivers. There will never be enough time or money to fully train a novice driver through public institutions. There will always be the need for additional supervised oversight during initial training. Research has shown that parents and other guardians have great potential to influence youngsters. At a minimum, adults through their own driving behaviors provide models (positive and negative) to novice drivers. Research also has documented that there are multiple problems in using parents and guardians to enhance the training and learning of young drivers. For example, there are households where available adults work and report that they do not have the time nor inclination to provide guided supervised driver training. However, because the potential positive benefits far outweigh the negative, educators are attempting to include parents and guardians in all aspects of educating young students.

A leader in this effort is the U.S. Department of Education's, Office of Educational Research and Improvement. Grants are being given to local education agencies through the Fund for the Improvement and Reform of Schools and Teaching (FIRST), started in 1988. A primary goal of this program is to increase the role of parents and guardians in the education of students.

Concerning parents and driver education, a number of states and insurance companies have programs or are renewing efforts to develop and initiate programs that involve the parents or guardians of new drivers. For example, Pennsylvania is testing an improved driver education program in nine school districts. One major component of this new program is parent participation. A large insurance company has initiated a program in the Southern California area where parents who are policy holders participate in a training program to assist in the education of their new drivers. Several education districts in Washington State have developed parent/student guides, procedures, and supporting materials to strongly encourage parents and guardians to participate in the training of their novice drivers.

For the new proposed education and licensing system, research will be done to develop better ways to involve parents and other adult drivers in the education and building of safe driving habits for novices. This involvement would be under the restrictions of a graduated licensing system and would provide additional supervised driving under a variety of traffic conditions.

The results of on-going activities will be used in the development of materials and procedures. It is expected that these on-going programs will provide the majority of data needed for the proposed effort. Thus, the need for an extended effort to research parent participation is not expected. The intent is to develop materials and procedures to be used by parents or guardians to provide supervised driving during the learning process. This effort also will determine whether this supervised practice can be integrated into the two-stage 
driver education program as well as into the graduated licensing. The improved procedures will be pilot tested as a part of the two-stage driver education pilot test.

\section{Innovative Simulation Technology}

Electronic technology, especially computer technology is progressing almost faster than one can keep tabs on it. It sometimes seems that before equipment can be plugged-in, something "newer and better" is available to replace it.

It has been over 10 years since the NHTSA has conducted any research concerning how best to teach safe driving to novices. During this period, there has been tremendous development of various simulation technologies for space and military applications. With the down-sizing of the military in particular, there is renewed interest from a number of companies to use this technology in other ways. Some of this simulation technology might be very successfully applied to meeting some of the needs in the driver education field.

Most young individuals have grown up in an electronic environment. For example, they are comfortable, and often very skilled, in interacting with a variety of electronic media from VCRs to home computers. It is hoped that effective procedures can be developed that could take advantage of this knowledge and apply it towards learning safe driving skills. It is not the intent to develop large simulators, but use readily available electronics to provide safe driving skills to new drivers. The proposed efforts will review the current simulation technology to determine the best and most cost-effective use in the training of novice drivers. Those applications which have potential will be further developed or redefined and then tested. Final testing will be done as a part of the graduated licensing system demonstration. 
Table 1

Overview

\begin{tabular}{|c|c|c|c|c|c|c|c|}
\hline & FY93 & FY94 & FY95 & FY96 & FY97 & FY98 & FY99 \\
\hline \multicolumn{8}{|c|}{$\begin{array}{l}\text { Graduated Licensing } \\
\text { o Component Evaluation }\end{array}$} \\
\hline \multicolumn{8}{|c|}{ o Total System Evaluation } \\
\hline \multicolumn{8}{|c|}{$\begin{array}{l}\text { Risk Taking Research } \\
\text { o Youthful Risk Taking }\end{array}$} \\
\hline \multicolumn{8}{|c|}{ o Decision Making (Dr.Ed.) } \\
\hline \multicolumn{8}{|c|}{ o Continued Risk Research } \\
\hline \multicolumn{8}{|c|}{$\begin{array}{l}\text { Two-Staged Driver Education } \\
\text { o Initial Development }\end{array}$} \\
\hline \multicolumn{8}{|l|}{ o Pilot Test ${ }^{2}$} \\
\hline \multicolumn{8}{|c|}{$\begin{array}{l}\text { Parent Participation } \\
\text { o Procedural Development }\end{array}$} \\
\hline \multicolumn{8}{|l|}{ o Pilot Test ${ }^{2}$} \\
\hline \multicolumn{8}{|l|}{ o Evaluation ${ }^{1}$} \\
\hline \multicolumn{7}{|c|}{ Innovative Simulation } & \\
\hline \multicolumn{8}{|l|}{ o Development } \\
\hline
\end{tabular}

(1) Included in Graduated License System Evaluation. (2) Included in the Two-Staged Driver Education Pilot Test 


\section{BACKGROUND MATERIALS}

"The Driver Education Evaluation Program (DEEP) Study," Report to Congress, National Highway Traffic Safety Administration, 1975.

"The Driver Education Evaluation Program (DEEP) Study," Report to Congress, National Highway Traffic Safety Administration, 1976.

"Evaluation of Safe Performance Secondary School Driver Education Curriculum Demonstration Project," Battelle Columbus Laboratories, for DeKalb County Board of Education, Decatur, GA and the National Highway Traffic Safety Administration, 1983.

"Driver Education Status Report (1984)," School and College Department, National Safety Council, 1985.

"Driver Education: Fifty Years of Youth Instruction," Public Technology, Inc., for The American Automobile Association Foundation for Traffic Safety, 1986.

"Summary of Preliminary Results: Follow-up Evaluation of The Safe Performance Curriculum Driver Education Project," Presentation to the American Driver \& Traffic Safety Association Annual Conference, Spokane, WA, 1987.

"Commitment to Action: Highway Safety Forum on Older Drivers and Pedestrians and Younger Drivers," National Safety Council, Baltimore, Maryland, 1989.

"An Improved Driver Entry System For Young Novice Drivers," Guidelines for Motor Vehicle Administrators, In cooperation with the American Association of Motor Vehicle Administrators, National Highway Traffic Safety Administration, 1989.

"Young Adult Highway Safety Plan," National Highway Traffic Safety Administration, 1990.

"New To The Road. Young Drivers and Novice Drivers: Similar Problems and Solutions?" Traffic Injury Research Foundation of Canada, 1990.

"New To The Road. Prevention Measures For Young or Novice Drivers," International Symposium, Insurance Bureau of Canada, Halifax, Nova Scotia, Canada, 1991.

"Addressing The Safety Issues Related To Younger And Older Drivers," Report to Congress, National Highway Traffic Safety Administration, 1993.

"Workshop To Identify Training Requirements Designed To Reduce Young Driver Risk Taking And Improve Decision Making Skills," Walcoff \& Associates, Inc., for the National Highway Traffic Safety Administration, 1993. 